\title{
Production of Gallium-68 with Medium to Low Energy Cyclotrons: What Opportunities for the Development of PET Radiotracers in Senegal?
}

\author{
Papa Mady Sy*, Mounibé Diarra* \\ Laboratory of Physics and Pharmaceutical Biophysics, Faculty of Medicine, Pharmacy and Odontology, UCAD, Dakar, Senegal \\ Email: *papamady.sy@ucad.edu.sn, *mounibe.diarra@ucad.edu.sn
}

How to cite this paper: Sy, P.M. and Diarra, M. (2022) Production of Gallium-68 with Medium to Low Energy Cyclotrons: What Opportunities for the Development of PET Radiotracers in Senegal? Journal of Modern Physics, 13, 267-273.

https://doi.org/10.4236/jmp.2022.133018

Received: January 28, 2022

Accepted: February 27, 2022

Published: March 2, 2022

Copyright $\odot 2022$ by author(s) and Scientific Research Publishing Inc. This work is licensed under the Creative Commons Attribution International License (CC BY 4.0).

http://creativecommons.org/licenses/by/4.0/

\begin{abstract}
This study focuses on the development possibilities of radiotracers used in PET in Senegal. This is a literature review that develops the production of 68-Gallium $\left({ }^{68} \mathrm{Ga}[\mathrm{Ga}]\right)$ via a medium to low energy cyclotron. It shows the possibility of producing ${ }^{68} \mathrm{Ga}[\mathrm{Ga}]$ with a simple production reaction using a target of ${ }^{68} \mathrm{Zn}$. This reaction provides high production yields, at the end of the bombardment (EOB), reaching up to 80 times the activity of a generator. PET imaging may offer better sensitivity and spatial resolution compared to SPECT which is currently used in Senegal. The acquisition of this type of medium to low energy accelerator in Senegal may constitute an important phase in the development of radiotracers with the objective of installing a PET imaging. However, solutions must be provided to minimize the presence of isotopic impurities.
\end{abstract}

\section{Keywords}

Gallium-68, PET, Radiotracers, Cyclotron, Senegal

\section{Introduction}

Gallium ( $\mathrm{Ga}$ ) is a chemical element belonging to the family of post-transition metals (group 13 of the periodic table of the elements). It is a silvery-looking metal with a melting point of $29.8^{\circ} \mathrm{C}$ [1] [2]. Gallium has two stable isotopes, ${ }^{69} \mathrm{Ga}$ and ${ }^{71} \mathrm{Ga}\left(61.1 \%\right.$ and $39.9 \%$ of natural gallium, respectively). ${ }^{68} \mathrm{Ga}[\mathrm{Ga}]$ (physical half-life of 67.71 minutes) combines two decay modes: electron capture (10\% to $12 \%$ ) and beta + decay ( 88 to $90 \%$ ) (Table 1 ) to give ${ }^{68}$ Zinc.

The $\beta+$ type decay results in the emission of a positron allowing the formation of two annihilation photons, essential for PET (positron emission tomography) imaging [1] [3] [4]. 
Table 1. Main emissions of ${ }^{68} \mathrm{Ga}[\mathrm{Ga}$ ] [1] [3] [4].

\begin{tabular}{cc}
\hline & Gallium 68 \\
\hline Gamma emission & $\gamma_{\text {annihilation }}=511 \mathrm{keV} ; \gamma_{\text {transition }}=1077.34 \mathrm{keV}(3.22 \%)$ \\
$\beta+$ & $E_{\beta \operatorname{mox}}=836 \mathrm{keV} ; E_{\beta \max }=1899 \mathrm{keV}$ \\
\hline
\end{tabular}

While PET is becoming more and more accessible, ${ }^{68} \mathrm{Ga}[\mathrm{Ga}]$ has the advantage of being a metal and therefore of offering possibilities different from those of halogens, by its way of binding to other atoms (chemistry of coordination), which makes it more versatile.

Currently, ${ }^{68} \mathrm{Ga}[\mathrm{Ga}]$ is mainly produced from a ${ }^{68} \mathrm{Ge}[\mathrm{Ge}] /{ }^{68} \mathrm{Ga}[\mathrm{Ga}]$ generator. The ${ }^{68} \mathrm{Ge}[\mathrm{Ge}] /{ }^{68} \mathrm{Ga}[\mathrm{Ga}]$ generator remains practical, because it guarantees the supply of ${ }^{68} \mathrm{Ga}[\mathrm{Ga}]$ for several months $\left({ }^{68} \mathrm{Ge}[\mathrm{Ge}]\right.$ physical period: 270.82 days). However, the use of the generator can be limited by its activity (typically 1.85 GBq of nominal activity when new); the minimum interval between elutions (typically 3 - 4 hours); the elution efficiency ( $60 \%-80 \%)$; and the potential for the parent radionuclide to be long-lived $\left({ }^{68} \mathrm{Ge}[\mathrm{Ge}]\right)$ crosses the column and ends up in the eluate (breakthrough) [5] [6] [7] [8].

Taking these considerations into account, Jensen and Clark [9] have developed an innovative method to meet the growing demand for ${ }^{68} \mathrm{Ga}[\mathrm{Ga}]$. This method consisted in producing ${ }^{68} \mathrm{Ga}[\mathrm{Ga}]$ via a cyclotron with a liquid target consisting of a solution of ${ }^{68} \mathrm{ZnCl}_{2}$ [9]. Since then, other research groups have attempted to optimize the production of ${ }^{68} \mathrm{Ga}[\mathrm{Ga}$ ] with a liquid target [5] [10]. Although the production of ${ }^{68} \mathrm{Ga}[\mathrm{Ga}]$ via a liquid target is facilitated by the target preparation process, the activity of ${ }^{68} \mathrm{Ga}[\mathrm{Ga}]$ available at the end of production is not significantly higher than that produced by the generator. To overcome the limitations seen with the use of a liquid target, a solid (enriched) target can dramatically improve the overall production of ${ }^{68} \mathrm{Ga}[\mathrm{Ga}]$. Precisely, the objective of this bibliographical synthesis is therefore to highlight the production of ${ }^{68} \mathrm{Ga}[\mathrm{Ga}]$ via a cyclotron by the use of a solid target (nature of the target, irradiation and production rate, quality of the radioelement produced, various impurities observed...).

\section{Ways of Producing ${ }^{68} \mathrm{Ga}[\mathrm{Ga}]$ from a cyclotron, Medium to Low Energy}

Several methods of producing ${ }^{68} \mathrm{Ga}[\mathrm{Ga}]$ have been developed using cyclotrons. Considering the type of particles typically accelerated in medium to low energy accelerators, four reactions can efficiently produce ${ }^{68} \mathrm{Ga}[\mathrm{Ga}]$, namely:

${ }^{65} \mathrm{Cu}(\alpha, \mathrm{n}){ }^{68} \mathrm{Ga}$ on a copper target, ${ }^{68} \mathrm{Zn}(\mathrm{p}, \mathrm{n}){ }^{68} \mathrm{Ga},{ }^{68} \mathrm{Zn}(\mathrm{d}, 2 \mathrm{n}){ }^{68} \mathrm{Ga}$ and ${ }^{70} \mathrm{Zn}(\mathrm{p}, 3 \mathrm{n}){ }^{68} \mathrm{Ga}$ on zinc targets [11] [12].

According to evaluations by Szelecsényi and al. and Sadeghi et al. [11] [13] based on the study of the cross section (maximum values of the cross sections: $882.0 \pm 98.5$ milli-barns for $17.2 \pm 1.2 \mathrm{MeV}$ with $\alpha$ particle on ${ }^{65} \mathrm{Cu}[\mathrm{Cu}]$ target et $911.3 \pm 99.4$ milli-barns for $12.2 \pm 1.3 \mathrm{MeV}$ with a proton on ${ }^{68} \mathrm{Zn}$ target) 
(Figure 1), the reactions ${ }^{65} \mathrm{Cu}(\alpha, \mathrm{n}){ }^{68} \mathrm{Ga}$ and ${ }^{68} \mathrm{Zn}(\mathrm{p}, \mathrm{n}){ }^{68} \mathrm{Ga}$ are the best to produce ${ }^{68} \mathrm{Ga}[\mathrm{Ga}]$ from of a medium to low energy accelerator.

In addition, among these two nuclear reactions, the irradiation of $\mathrm{Zn}$ by protons $\left({ }^{68} \mathrm{Zn}[\mathrm{Zn}](\mathrm{p}, \mathrm{n}){ }^{68} \mathrm{Ga}[\mathrm{Ga}]\right)$ is the preferred one (the one we have also chosen) according to several studies because it leads to a higher production yield with less impurities and uses protons, the simplest of all cyclotron projectiles [5] [11] [13] [15].

\section{Production of ${ }^{68} \mathrm{Ga}[\mathrm{Ga}]$ via a Cyclotron Using a Solid Target of ${ }^{68} \mathrm{Zn}[\mathrm{Zn}]$}

\subsection{Nature of the Target}

Aiman $\mathrm{H}$. Alnahwi et al. [16] developed an automated ${ }^{68} \mathrm{Ga}[\mathrm{Ga}]$ radiosynthesis for routine large-scale production using a squeezed ${ }^{68} \mathrm{Zn}[\mathrm{Zn}]$ target (target highly enriched to 99.26 in ${ }^{68} \mathrm{Zn}[\mathrm{Zn}]$ ) (Table 2).
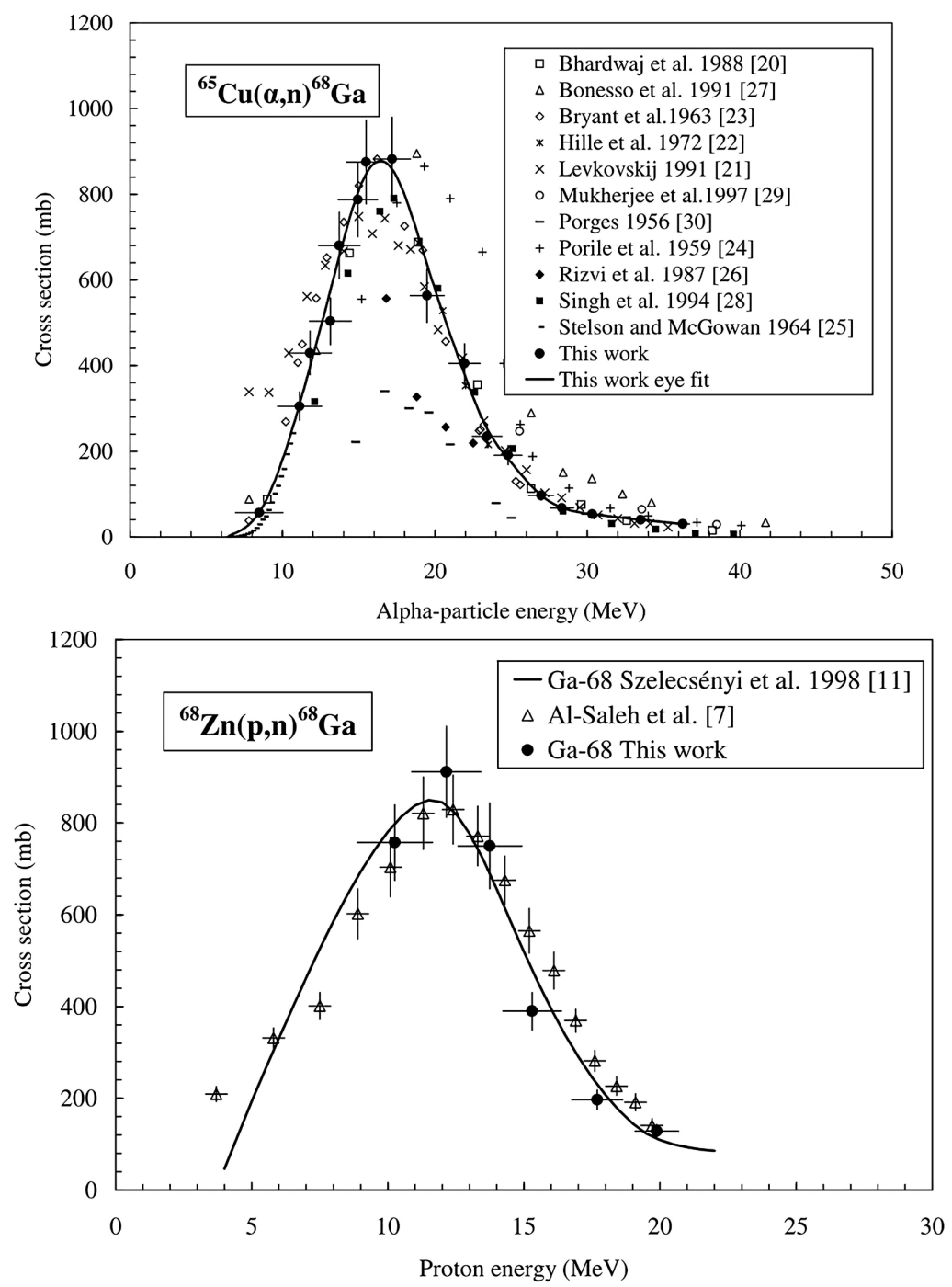

Figure 1. Cross sections of reactions ${ }^{65} \mathrm{Cu}[\mathrm{Cu}](\alpha, \mathrm{n}){ }^{68} \mathrm{Ga}[\mathrm{Ga}]$ and ${ }^{68} \mathrm{Zn}[\mathrm{Zn}](\mathrm{p}, \mathrm{n})$ ${ }^{68} \mathrm{Ga}[\mathrm{Ga}][11][14]$. 
Table 2. Isotopic composition of the target and impurities [16].

\begin{tabular}{|c|c|c|c|c|c|c|c|c|}
\hline $\mathrm{Zn}(\%)$ & ${ }^{64} \mathrm{Zn}(0.01)$ & ${ }^{66} \mathrm{Zn}(0.1)$ & ${ }^{67} \mathrm{Zn}(0.61)$ & ${ }^{68} \mathrm{Zn}(99.26)$ & ${ }^{70} \mathrm{Zn}(0.02)$ & & & \\
\hline \multirow{2}{*}{$\begin{array}{l}\text { Impureties } \\
\text { (ppm) }\end{array}$} & $\mathrm{Al}(<1)$ & $\mathrm{Cu}(5.3)$ & $\mathrm{Fe}(220)$ & $\operatorname{Cr}(20.3)$ & $\operatorname{Sn}(170)$ & Co $(<1)$ & $\mathrm{Ca}(<5)$ & Cd (125) \\
\hline & $\mathrm{Pb}(3.6)$ & As $(<0.1)$ & $\mathrm{Si}(4)$ & $\operatorname{Mg}(1.8)$ & Mn (1.17) & K (13) & $\mathrm{Na}(2.7)$ & \\
\hline
\end{tabular}

Thus, ${ }^{68} \mathrm{Zn}[\mathrm{Zn}]$ pellets of different diameter and thickness were prepared (diameter: 6 to $10 \mathrm{~mm}$ and thickness: 0.51 to $0.55 \mathrm{~mm}$ ). The target carrier was made of aluminum, so it was only weakly activated by the proton beam from the cyclotron according to these authors. In addition, aluminum, due to its thermal conductivity properties [17] [18], allowed efficient cooling of the target during irradiation.

In another study, Lin et al. [8] used an enriched ${ }^{68} \mathrm{Zn}[\mathrm{Zn}$ ] target $(60-120 \mathrm{mg})$ with a diameter of $7 \mathrm{~mm}$. The target was electrodeposited on a platinum disc and then it was transferred and mounted in the cyclotron PETtrace via the module Comecer EDS/PTS (Castel Bolognese RA, Italy).

\subsection{Target Irradiation and Production Efficiency}

Aiman H. Alnahwi et al. [16] used irradiations with a beam current between 5 and $35 \mu \mathrm{A}$ on the squeezed ${ }^{68} \mathrm{Zn}[\mathrm{Zn}]$ target with an energy ranging from 13 to 14.5 MeV for a duration of 90 minutes. The irradiations were first carried out on a $6 \mathrm{~mm}$ target for which the production yield (corrected for the decay) was 2.6 $\mathrm{GBq} / \mu \mathrm{A} \cdot \mathrm{h}$. The activity of ${ }^{68} \mathrm{Ga}[\mathrm{Ga}]$ increased when the current applied to the target was greater (input $1-3$ ). The highest production yields were obtained with the 8- and 10-mm targets (entries 4 - 5). Using a current of $35 \mu \mathrm{A}, 145 \pm 6$ GBq (at EOB: end of bombardment) was produced (input 6) (Table 3). This value (145 $\pm 6 \mathrm{GBq}$ in $\mathrm{EOB}$ ) is superior to the values reported by Lin et al. (Lin, Waligorski, et Lepera 2018) which used an incident energy of $14.5 \mathrm{MeV}$ proton beam with beam currents of 15 à $40 \mu \mathrm{A}$ and a power equivalent to about 80 times the activity of a generator.

Other authors like Sadeghi et al. [13] obtained interesting yield values for the ${ }^{68} \mathrm{Zn}[\mathrm{Zn}](\mathrm{p}, \mathrm{n}){ }^{68} \mathrm{Ga}[\mathrm{Ga}]$ nuclear reaction using a solid target of $\mathrm{Zn}$ enriched to $97 \%$ in ${ }^{68} \mathrm{Zn}[\mathrm{Zn}]$. Their EOB yield reached $5.032 \mathrm{GBq} / \mu \mathrm{Ah}$ at $15 \mathrm{MeV}$ with the use of a target of $52 \mu \mathrm{m}$ thick; with an irradiation time of $0.25 \mathrm{~h}$ and a beam current of $150 \mu \mathrm{A}$. Szelecsényi et al. [11] reported that their values, calculated with the cross sections $(5.809 \mathrm{GBq} / \mu \mathrm{Ah})$, were in agreement with these data.

\subsection{Dissolving the Target}

After facilitated transport via magnetic media (Automated Target Transfer System [12]), immediate dissolution of the target should be performed for rapid transfer to the purification column. $7 \mathrm{~N}$ nitric acid $\mathrm{HNO}_{3}$ can be used for target dissolution. Another particularly interesting method for extracting radioisotopes of gallium from zinc targets is the thermal diffusion method described by Tolmachev and Lundqvist [19]. A similar method was also employed by Zeisler et al. [20]. 
Table 3. Production yields [8] [16].

\begin{tabular}{ccccccc}
\hline Entry & $\begin{array}{c}\text { Pressed target } \\
\text { diameter } \\
(\mathrm{mm})\end{array}$ & $\begin{array}{c}\text { Energy Ep } \\
(\mathrm{MeV})\end{array}$ & $\begin{array}{c}\text { Maximum } \\
\text { current on } \\
\text { target }(\mu \mathrm{A})\end{array}$ & $\begin{array}{c}\text { Activity } \\
(\mathrm{GBq})^{\mathrm{b}}\end{array}$ & $\begin{array}{c}\text { Production } \\
\text { yield } \\
(\mathrm{GBq} / \mu \mathrm{A} \cdot \mathrm{h})\end{array}$ & $\begin{array}{c}\text { Saturation } \\
\text { yield } \\
(\mathrm{GBq} / \mu \mathrm{A})\end{array}$ \\
\hline $\mathbf{1}$ & 6 & 14 & 5 & 7.2 & 2.6 & 5.1 \\
2 & 6 & 14 & 12 & 17.0 & 2.2 & 4.3 \\
$\mathbf{3}$ & 6 & 14 & 25 & 32.8 & 2.6 & 5.0 \\
$\mathbf{4}$ & 8 & 14 & 15 & 36.6 & 4.8 & 9.0 \\
5 & 10 & 14 & 30 & 68.6 & 4.6 & 8.7 \\
6 & 10 & 13 & $35^{\mathrm{c}}$ & $144.8 \pm 6.4$ & $2.7 \pm 0.1$ & $6.8 \pm 0.1$ \\
7 (Lin) & 7 & 14.5 & 30 & $60.9 \pm 1.8$ & $2.7 \pm 0.1$ & $5.6 \pm 0.2^{\mathrm{d}}$ \\
\hline
\end{tabular}

${ }^{a}$ The proton beam energies were calculated by Monte Carlo simulation using SRIM. Irradiation time was fixed at $30 \mathrm{~min}$. ${ }^{\text {b}}$ Total recovered activity, corrected at EOB. 'Irradiation time was $90 \mathrm{~min}$. dSaturation yield estimated from results reported by Lin et al. [8]. Entries $1-5, \mathrm{n}=1$; entry $6, \mathrm{n}=2$.

\subsection{Purification of ${ }^{68} \mathrm{Ga}[\mathrm{Ga}]$}

The automated purification process implemented by Aiman H. Alnahwi et al. [16] used a hydroxamate resin. $0.01 \mathrm{~N} \mathrm{HCl}$ solution $(50 \mathrm{~mL})$ was required to remove ${ }^{68} \mathrm{Zn}[\mathrm{Zn}]$. The ${ }^{68} \mathrm{Ga}[\mathrm{Ga}]$ was then eluted from the hydroxamate resin with $0.75 \mathrm{~N} \mathrm{HCl}$ as $\left[{ }^{68} \mathrm{Ga}\right] \mathrm{GaCl}_{3}$. This provides ${ }^{68} \mathrm{Ga}[\mathrm{Ga}]$ with a high radiochemical yield and a lead time of the dissolution and purification method of less than 10 - $12 \mathrm{~min}$ (20 $\mathrm{min}$ for Lin et al. [8]). The last purification step, carried out with the CUBCX resin [21], has already been validated internally.

\subsection{Metallic and Isotopic Impurities}

Aiman H. Alnahwi et al. [16] described the presence of metal impurities after purification. For all batches tested, metallic impurities were below the general limit of $10 \mathrm{ppm}$ and $20 \mathrm{ppm}$ for heavy metals (USP and Ph. Eur.). The concentrations of impurities of antimony, barium, beryllium, bismuth, cadmium, chromium, cobalt, lead, lithium, molybdenum, selenium, silver, tin, titanium, vanadium were $<0.5 \mathrm{ppm}$. The elements $\mathrm{Al}, \mathrm{Fe}, \mathrm{Mg}, \mathrm{Zn}$ and $\mathrm{Cu}$ were $<4 \mathrm{ppm}$.

The main isotopic impurities were identified by gamma spectrometry $(29,50$ and $72 \mathrm{~h}$ post purification) and consisted of ${ }^{67} \mathrm{Ga}[\mathrm{Ga}$ ] (physical period: 3.26 days) and ${ }^{66} \mathrm{Ga}[\mathrm{Ga}$ ] (physical period: $9.45 \mathrm{~h}$ ), as indicated previously by Al-Saleh et al. [22] [23] and their total combined amount was less than $2 \%$ at $6 \mathrm{~h}$ after irradiation (Energy $13 \mathrm{MeV}$ ). ${ }^{67} \mathrm{Ga}[\mathrm{Ga}]$ can be produced via the reactions ${ }^{67} \mathrm{Zn}[\mathrm{Zn}]$ $(\mathrm{p}, \mathrm{n}){ }^{67} \mathrm{Ga}[\mathrm{Ga}]$ and ${ }^{68} \mathrm{Zn}[\mathrm{Zn}](\mathrm{p}, 2 \mathrm{n}){ }^{67} \mathrm{Ga}[\mathrm{Ga}]$ with incident proton energy of 2 $26 \mathrm{MeV}$ and $13-29.5 \mathrm{MeV}$, respectively. ${ }^{66} \mathrm{Ga}$ [Ga] can be produced via ${ }^{66} \mathrm{Zn}[\mathrm{Zn}]$ $(\mathrm{p}, \mathrm{n}){ }^{66} \mathrm{Ga}[\mathrm{Ga}]$ and ${ }^{67} \mathrm{Zn}[\mathrm{Zn}](\mathrm{p}, 2 \mathrm{n}){ }^{66} \mathrm{Ga}[\mathrm{Ga}]$ with incident particle energy of 6 $26 \mathrm{MeV}$ and $15-26 \mathrm{MeV}$, respectively [24]. According to the experimental measurements reported by Alves et al. [5], the amounts of ${ }^{67} \mathrm{Ga}[\mathrm{Ga}]$ and ${ }^{66} \mathrm{Ga}[\mathrm{Ga}]$ can be kept below $2 \%$ using a particle energy of $13 \mathrm{MeV}$. For example, the 
${ }^{68} \mathrm{Ga}[\mathrm{Ga}$ ] purities may be $99.97 \%$ and $99.99 \%$ at EOB for particle energies of 14 and $13 \mathrm{MeV}$ respectively. These values were confirmed by Lin et al. [8] who observed a small fraction $(\leq 0.2 \%)$ of ${ }^{67} \mathrm{Ga}[\mathrm{Ga}]$ when the target was irradiated for up to 90 min with $14.5 \mathrm{MeV}$ protons.

\subsection{Target Recovery}

Many authors have not performed a target recovery process, believing it to be more expensive than buying a new target. However, according to an IAEA document [12], ${ }^{68} \mathrm{Zn}[\mathrm{Zn}]$ can easily be recovered provided no impurities (e.g. iron) are present. Thus, simple multiple drying with nitric acid can be performed as described below. The procedure includes: 1) dry evaporation; 2) Dilution in concentrated nitric acid ( $>10 \mathrm{M})$; 3) Repeat the evaporation; 4) Dilution in 10 $\mathrm{mM}$ nitric acid; and 5) Evaporation to dryness or preparation of a ready-to-use solution. $>90 \%$ recovery of the ${ }^{68} \mathrm{Zn}$ isotope of Zinc is expected. All reagents used must be of high quality, traces of metal.

Buying a new target is worth more than this long and tedious target recovery process.

\section{Conclusion}

The acquisition of a medium to low energy cyclotron can be a huge opportunity for developing African countries including Senegal. The production technique is quite accessible. Obtaining gallium could initiate the development of new PET radiotracers hitherto unused, particularly ${ }^{68} \mathrm{Ga}[\mathrm{Ga}]-\mathrm{PSMA}$ (prostate specific membrane antigen), now essential in the diagnosis of prostate cancer. The objective of developing these radiotracers and the installation of a PET are today major challenges and issues for Senegal. Thus, the production of ${ }^{68} \mathrm{Ga}[\mathrm{Ga}]$ via a cyclotron therefore constitutes an innovative and interesting method with high production yields. However, it must be optimized to reduce or even eliminate isotopic impurities.

\section{Conflicts of Interest}

The authors declare no conflicts of interest regarding the publication of this paper.

\section{References}

[1] Casagrande, K. (2018) 68Ga-PSMA-11, nouveau traceur TEP pour l'imagerie du cancer de la prostate: Synthèse, contrôles qualité et dossier d'autorisation. Exercice, Université Toulouse III-Paul Sabatier.

[2] Downs, A.J. (1993) Chemistry of Aluminium, Gallium, Indium and Thallium. Springer Science \& Business Media, Berlin. https://doi.org/10.1007/978-94-011-2170-5

[3] Velikyan, I. (2015) Molecules, 20, 12913-12943. https://doi.org/10.3390/molecules200712913

[4] Baldik, R. and Dombayci, A. (2016) Applied Radiation and Isotopes, 113, 10-17. 
https://doi.org/10.1016/j.apradiso.2016.04.002

[5] Alves, F., et al. (2017) AIP Conference Proceedings, 1845, Article ID: 020001. https://doi.org/10.1063/1.4983532

[6] IAEA (2010) Production of Long Lived Parent Radionuclides for Generators: ${ }^{68} \mathrm{Ge}$, ${ }^{82} \mathrm{Sr},{ }^{90} \mathrm{Sr}$ and ${ }^{188} \mathrm{~W}$. International Atomic Energy Agency, Vienna.

[7] Belosi, F., et al. (2013) Current Radiopharmaceuticals, 6, 72-77. https://doi.org/10.2174/1874471011306020002

[8] Lin, M., Waligorski, G.J. and Lepera, C.G. (2018) Applied Radiation and Isotopes, 133, 1-3. https://doi.org/10.1016/j.apradiso.2017.12.010

[9] Jensen, M. and Clark, J. (2011) Direct Production of Ga-68 from Proton Bombardment of Concentrated Aqueous Solutions of [Zn-68] Zinc Chloride. The 13th International Workshop on Targetry and Target Chemistry Proceedings, Roskilde, 26-28 July 2010, 288-292.

https://orbit.dtu.dk/en/publications/direct-production-of-ga-68-from-proton-bomb ardment-of-concentrate

[10] Pandey, M.K., Byrne, J.F., Jiang, H., Packard, A.B. and DeGrado, T.R. (2014) American Journal of Nuclear Medicine and Molecular Imaging, 4, 303-310.

[11] Szelecsényi, F., Kovács, Z., Nagatsu, K., Fukumura, K., Suzuki, K. and Mukai, K. (2012) Radiochimica Acta, 100, 5-11. https://doi.org/10.1524/ract.2011.1896

[12] IAEA (2019) Gallium-68 Cyclotron Production. IAEA, Vienna.

[13] Sadeghi, M., Kakavand, T., Mokhtari, L. and Gholamzadeh, Z. (2009) Pramana, 72, 335-341. https://doi.org/10.1007/s12043-009-0029-4

[14] Tárkányi, F.T., et al. (2019) Journal of Radioanalytical and Nuclear Chemistry, 319, 533-666. https://doi.org/10.1007/s10967-018-6380-5

[15] Gilly, L.J., Henriet, G.A., Alves, M.P. and Capron, P.C. (1963) Physical Review, 131, 1727-1731. https://doi.org/10.1103/PhysRev.131.1727

[16] Alnahwi, A.H., Tremblay, S., Ait-Mohand, S., Beaudoin, J.-F. and Guérin, B. (2020) Applied Radiation and Isotopes, 156, Article ID: 109014. https://doi.org/10.1016/j.apradiso.2019.109014

[17] Alnahwi, A.H., Tremblay, S. and Guérin, B. (2018) Applied Sciences, 8, 1579. https://doi.org/10.3390/app8091579

[18] Lin, M., Mukhopadhyay, U., Waligorski, G.J., Balatoni, J.A. and González-Lepera, C. (2016) Applied Radiation and Isotopes, 107, 317-322. https://doi.org/10.1016/j.apradiso.2015.11.016

[19] Tolmachev, V. and Lundqvist, H. (1996) Applied Radiation and Isotopes, 47, 297-299. https://doi.org/10.1016/0969-8043(95)00290-1

[20] Zeisler, S., Limoges, A., Kumlin, J., Siikanen, J. and Hoehr, C. (2019) Instruments, 3, 10. https://doi.org/10.3390/instruments3010010

[21] Mueller, D., Klette, I., Baum, R.P., Gottschaldt, M., Schultz, M.K. and Breeman, W.A.P. (2012) Bioconjugate Chemistry, 23, 1712-1717. https://doi.org/10.1021/bc300103t

[22] Al-Saleh, F.S., Al Mugren, K.S. and Azzam, A. (2007) Applied Radiation and Isotopes, 65, 1101-1107. https://doi.org/10.1016/j.apradiso.2007.05.004

[23] Engle, J.W., et al. (2012) Applied Radiation and Isotopes, 70, 1792-1796. https://doi.org/10.1016/j.apradiso.2012.03.030

[24] Szelecsényi, F., Boothe, T.E., Takács, S., Tárkányi, F. and Tavano, E. (1998) Applied Radiation and Isotopes, 49, 1005-1032. https://doi.org/10.1016/S0969-8043(97)10103-8 